Original paper

\title{
Awareness of medical radiation exposure among patients: A patient survey as a first step for effective communication of ionizing radiation risks
}

\author{
F. Ria ${ }^{a, b, c, *}$, A. Bergantin ${ }^{a}$, A. Vai ${ }^{a, b}$, P. Bonfanti ${ }^{a}$, A.S. Martinotti ${ }^{\mathrm{a}}$, I. Redaelli ${ }^{\mathrm{a}}$, M. Invernizzi $^{\mathrm{a}}$, \\ G. Pedrinelli ${ }^{\mathrm{a}}$, G. Bernini ${ }^{\mathrm{b}}$, S. Papa ${ }^{\mathrm{a}}$, E. Samei ${ }^{\mathrm{c}}$ \\ a Centro Diagnostico Italiano, Milano, Italy \\ $\mathrm{b}$ progettoDiventerò di Fondazione Bracco, Milano, Italy \\ c Carl E. Ravin Advanced Imaging Labs, Duke University and Clinical Imaging Physics Group, Duke University Health System, Durham NC, USA
}

\section{A R T I C L E I N F O}

\section{Keywords:}

Patient awareness

Radiation risk

Effective communication

\begin{abstract}
A B S T R A C T
Introduction: The European Directive 2013/59/EURATOM requires patient radiation dose information to be included in the medical report of radiological procedures. To provide effective communication to the patient, it is necessary to first assess the patient's level of knowledge regarding medical exposure. The goal of this work is to survey patients' current knowledge level of both medical exposure to ionizing radiation and professional disciplines and communication means used by patients to garner information.

Material and Methods: A questionnaire was designed comprised of thirteen questions: 737 patients participated in the survey. The data were analysed based on population age, education, and number of radiological procedures received in the three years prior to survey.

Results: A majority of respondents (56.4\%) did not know which modality uses ionizing radiation. $74.7 \%$ had never discussed with healthcare professionals the risk concerning their medical radiological procedures. $70.1 \%$ were not aware of the professionals that have expertise to discuss the use of ionizing radiation for medical purposes, and $84.7 \%$ believe it is important to have the radiation dose information stated in the medical report. Conclusion: Patients agree with new regulations that it is important to know the radiation level related to the medical exposure, but there is little awareness in terms of which modalities use X-Rays and the professionals and channels that can help them to better understand the exposure information. To plan effective communication, it is essential to devise methods and adequate resources for key professionals (medical physicists, radiologists, referring physicians) to convey correct and effective information.
\end{abstract}

\section{Introduction}

In the last sixty years, many scientific international institutions have worked in the effort to estimate and optimize the radiation risk in the work environment and in medical exposure [1-3]. In the last few years, European and American legislations have evolved in the direction of communicating the radiation risk related to the medical exposure directly to the patient [4-5]. On December 5, 2013, the Council of the European Union adopted Council Directive 2013/59/EURATOM laying down "Basic safety standards for protection against the dangers arising from exposure to ionizing radiation". One of the strongest innovative aspects introduced by the Directive is described under chapter 7 , article 58, paragraph (b), requiring Member States to ensure that "information relating to patient exposure forms part of the report of the medical radiological procedure". The approval of the Directive was preceded by a long period of discussion and debate among scientific communities (especially medical radiologists, nuclear medicine physicians, medical physics experts, and radiation protection experts) in European countries [6-8]. The general orientation now seems to passively comply with the European guidelines, that is to add the data relating to patient exposure to the medical report with little effort spent on effective communication.

Patient and physician awareness of radiation doses and their related risks is very low [9], despite the fact that human exposure to ionizing radiation comes second in importance to naturally occurring background radiation exposure [10-13]. Some studies have demonstrated that approximately $20 \%$ of primary care physicians believe that magnetic resonance imaging uses ionizing radiation. On average, cardiologists underestimate the dose of myocardial perfusion imaging by 300 to a thousand times [14]. Medical radiologists themselves underestimate the radiation doses associated with a CT scan by $50-500$ times [14] and $7 \%$ of the radiographers claim that mammography does not

\footnotetext{
* Corresponding author at: Carl E. Ravin Advanced Imaging Labs and Clinical Imaging Physics Group, Duke University Health System, Erwin Road, Suite 302, 27705, Durham NC, USA.

E-mail address: francesco.ria@duke.edu (F. Ria).
} 
use ionizing radiation [15]. Such faulty knowledge is transferred directly onto patients when they discuss the reasons for having a medical imaging test and its related risks with medical specialists [16-20]. Nonetheless, no one knows the real level of awareness and perception of the risk arising from ionizing radiation in patients receiving diagnostic radiological procedures. The upcoming developments of European regulations will enforce the requirement to state the absorbed dose of radiation in the report of medical radiological procedures. However, effective communication necessitates ensuring patient's minimum knowledge and understanding of mediation burden [21].

The goal of this work was to survey patients to assess the current level of knowledge about a number of issues relating to medical exposure to ionizing radiation among patients undergoing medical radiology procedures. In particular, the study aimed to verify whether or not patients know which imaging modalities deliver ionizing radiation; to investigate which professional disciplines and communication means are used by patients to garner information; and to understand the importance of dose reduction in concert with the quality of diagnostic imaging procedures.

\section{Materials and methods}

The tool identified to conduct the survey was a multiple choice questionnaire distributed to patients as they arrived to receive medical radiological procedures. The questionnaire was comprised of nine questions, plus an additional four questions concerning personal information about respondents in order to characterize the sample (Table 1).

The first question was aimed at defining whether there were different levels of awareness among patients who periodically underwent diagnostic procedures versus those who occasionally have had a diagnostic test. Questions 2, 3 and 4 were intended to survey the respondents' awareness of imaging modalities actually delivering X-rays, and whether patients were able to put them in the right order from the lowest to the highest amount of radiation delivered for diagnostic purposes. The purpose of the next three questions, i.e. 5, 6 and 7, was to enquire about the information channels used by patients or believed by patients to be suitable to provide information about radiation risks. Question 8 was intended to put radiology clients before an important choice, asking them to choose either one of the two options given. Question 9 asked respondents to express their agreement or disagreement with the requirement of the new EU Directive. The last four questions concerned the respondents' profile in terms of age, gender, education, and occupation.

In order to ensure consistency of responses the questionnaire was preceded with an introductory note that requested the patients not to ask medical staff and technicians for information about the questions included in the survey.

The questionnaire was distributed through patient registration at the desks of the Diagnostic Imaging Department of Centro Diagnostico Italiano (CDI) between September 18th 2014 and January 25th 2015. Based on previous customer satisfaction survey return rates, a total of three thousand forms were handed out with the goal to collect 500-1000 completed questionnaires. Respondents were asked to put the completed questionnaire in a box located near the exit from the facility. The questionnaires were read by a scanner capable of transferring the information directly to an electronic spreadsheet for later processing.

The data were analysed based on population age subdivided into four age groups $(18-25,26-45,46-65,66-90)$, education, and the number of diagnostic imaging procedures received in the three years prior to survey. The answers given by each subset were then studied

Table 1

Multiple choice questionnaire distributed to patients.

$\begin{array}{ll}\text { Question } & \text { Possible options }\end{array}$

1 How many diagnostic imaging procedures (CT scan, MRI, Ultrasound, X-rays, etc.) have you had in the last 3 years?

$\square$ None

$\square$ None

Are you aware that some diagnostic imaging tests are performed using X-rays, i.e. emitting ionizing radiation?

3 In your opinion, which of the following diagnostic imaging procedures use X-rays, i.e. involve the emission of ionizing radiation?

4 Please give the amount of X-rays (1-10), i.e. ionizing radiation, you believe is emitted during the performance of each of the following diagnostic imaging exams, where 1 is no radiation and 10 is a high level of radiation

5 Have you ever discussed with or asked any of the following health care professionals for information about risks arising from X-rays (ionizing radiation)?

6 Which of the following health care professionals do you believe to be the most suitable to provide information about risks arising from $\mathrm{X}$-rays (ionizing radiation)?

7 Have you ever searched yourself for information about the risk associated with ionizing radiation for medical purposes?

8 Which of the two options do you think is preferable for diagnostic purposes?

9 Do you believe it useful to have the information about the dose of X-rays (i.e. ionizing radiation) absorbed during your radiological procedure stated in your exam report?

10 Age in years

11 Gender

12 Education

13 Occupation

$\square$ Yes

$\square$ Ultrasound

$\square$ Mammography

$\square$ Radiography

$\square$ Magnetic resonance imaging

$\square$ Ultrasound

$\square$ Mammography

$\square$ Radiography

Medical physicist

$\square$ Nurse

$\square$ Family physician (gp)

$\square$ Medical physicist

$\square$ Nurse

$\square$ Family physician (gp)

$\square$ No search

$\square \mathrm{Tv}$

$\square$ Magazines/specialised

publications

$\square$ Reduce the dose of ionizing radiation delivered by radiologic equipment

$\square$ Enhance the quality of diagnostic images

$\square$ Yes

$\square$ No

18-90

$\square \mathrm{M}$

$\square$ No school degree

$\square$ Middle school

$\square$ Student

$\square$ Unemployed

$\square$ Blue-collar worker

$\square$ White-collar worke

$\square$ Middle manager $\square$ Don't know

$\square$ Two or more

$\square$ No

$\square$ CT scan

$\square$ None

$\square$ All

$\square$ Magnetic resonance imaging

$\square$ CT scan

$\square$ Medical radiologist

$\square$ Radiology technician

$\square$ None

$\square$ Medical radiologist

$\square$ Radiology technician

$\square$ None

$\square$ Internet

$\square$ Other

$\square \mathrm{F}$

High school

$\square$ University degree

$\square$ Executive employee

$\square$ Freelancer

$\square$ Pensioner

$\square$ Other 
Table 2

Respondents' opinion about diagnostic imaging equipment using ionizing radiation. Question 3.

\begin{tabular}{|c|c|c|c|c|c|c|c|c|c|c|}
\hline & US & MG & $\mathrm{X}$-rays & MRI & $\mathrm{CT}$ & None & All & No answer & Total & Total answers \\
\hline Number of answers & 42 & 320 & 555 & 259 & 375 & 6 & 82 & 47 & 737 & 690 \\
\hline$\%$ Of answers & 6.1 & 46.4 & 80.4 & 37.5 & 54.4 & 0.9 & 11.9 & & & \\
\hline
\end{tabular}

Table 3

Mean, and standard deviation values of the amount of radiation attributed to each diagnostic imaging modality by the sample of respondents, distributed by age groups.

\begin{tabular}{|c|c|c|c|c|c|c|c|c|c|c|c|c|}
\hline \multirow[b]{2}{*}{ Age group } & \multicolumn{4}{|c|}{ Ultrasound } & \multicolumn{4}{|c|}{ Mammography } & \multicolumn{4}{|l|}{$\mathrm{X}$-rays } \\
\hline & $18-25$ & $26-45$ & $46-65$ & $66-90$ & $18-25$ & $26-45$ & $46-65$ & $66-90$ & $18-25$ & $26-45$ & $46-65$ & $66-90$ \\
\hline Mean & 2.0 & 1.8 & 1.8 & 2.4 & 4.1 & 4.4 & 5.5 & 4.9 & 7.4 & 7.5 & 7.4 & 6.6 \\
\hline St. Dev & 2.1 & 1.5 & 1.8 & 2.5 & 2.8 & 2.7 & 3.0 & 3.2 & 2.6 & 2.3 & 2.5 & 3.0 \\
\hline
\end{tabular}

\begin{tabular}{|c|c|c|c|c|c|c|c|c|}
\hline \multirow[b]{2}{*}{ Age group } & \multicolumn{4}{|l|}{ MRI } & \multicolumn{4}{|l|}{ CT } \\
\hline & $18-25$ & $26-45$ & $46-65$ & $66-90$ & $18-25$ & $26-45$ & $46-65$ & $66-90$ \\
\hline Mean & 5.8 & 5.4 & 4.9 & 5.7 & 7.1 & 6.9 & 6.5 & 7.4 \\
\hline St. Dev & 3.7 & 3.5 & 3.5 & 3.4 & 3.6 & 3.1 & 3.3 & 2.8 \\
\hline
\end{tabular}

Table 4

Mean, and standard deviation values of the amount of radiation attributed to each diagnostic imaging modality by the sample of respondents, distributed by gender.

\begin{tabular}{|c|c|c|c|c|c|c|c|c|c|c|}
\hline \multirow[b]{2}{*}{ Gender } & \multicolumn{2}{|c|}{ Ultrasound } & \multicolumn{2}{|c|}{ Mammography } & \multicolumn{2}{|c|}{ X-rays } & \multicolumn{2}{|c|}{ MRI } & \multicolumn{2}{|l|}{$\mathrm{CT}$} \\
\hline & M & $\mathrm{F}$ & $\mathrm{M}$ & $\mathrm{F}$ & M & $\mathrm{F}$ & M & $\mathrm{F}$ & M & $\mathrm{F}$ \\
\hline Mean & 2.0 & 1.9 & 4.2 & 5.5 & 7.1 & 7.3 & 4.9 & 5.5 & 6.5 & 6.9 \\
\hline St. Dev & 1.9 & 1.8 & 2.8 & 3.0 & 2.6 & 2.6 & 3.3 & 3.6 & 3.1 & 3.2 \\
\hline
\end{tabular}

according to a consistency criterion, i.e., evaluating the relative ratios between the median values of dose amounts assigned by each subset to the various imaging modalities. In particular, the awareness of the subdivision of imaging modalities into ionizing and non-ionizing was analysed, as well as the approximate knowledge of the amount of X-rays delivered by the different types of diagnostic imaging procedures.

\section{Results}

Of all questionnaires distributed, 737 forms were returned (24.6\%). This level of participation was consistent with that of the customer satisfaction surveys at our institution (30\%).

The respondents who completed the survey, were aged between 18 and 90 years old $(\mathrm{Q} 1=45$; $\mathrm{Q} 3=65$; median $=55)$, with a prevalence of females over males (63.1\% versus $36.9 \%$ ). $10.3 \%$ of the respondents had not received any radiological procedure in the past three years,
$18.4 \%$ stated they had undergone one procedure, $71.3 \%$ had received two or more procedures. Almost half of the survey participants were educated up to high school (49.1\%), $27.9 \%$ were educated up to the graduate level, $21.6 \%$ were educated up to middle school, and $1.5 \%$ had not school degree. With regard to the respondents' occupation, $31.0 \%$ of them were retired, $24.9 \%$ were white-collar workers, $12.0 \%$ were freelancers, $8.5 \%$ middle managers, $6.2 \%$ executive employees, and $3.6 \%$ blue-collar workers. Students accounted for $1.9 \%$ of the sample, whereas the unemployed accounted for $4.3 \%$, and $7.5 \%$ stated they were employed in other occupations not mentioned in the questionnaire. With regard to the awareness of imaging modalities delivering X-rays, $89.9 \%$ of the respondents were aware of the fact that certain diagnostic imaging procedures use X-rays or ionizing radiation, whereas $4.1 \%$ were unaware thereof, and $6.1 \%$ did not answer the question. Drilling down into individual imaging modalities, the resulting data are summarized in the Table 2.

The data concerning magnetic resonance imaging was quite noticeable. Overall, almost half of the respondents believed that this equipment delivers ionizing radiation. Moreover, about 18\% thought the same about ultrasound. On the contrary, less than $60 \%$ believed that mammography uses X-rays.

As indicated earlier, the respondents were asked to provide an estimate of the amount of ionizing radiation emitted by each imaging modality for diagnostic purposes. The Tables 3-6 report the mean and the standard deviation values of the data collected, subdivided by age, gender, education, and number of diagnostic exams taken by the

Table 5

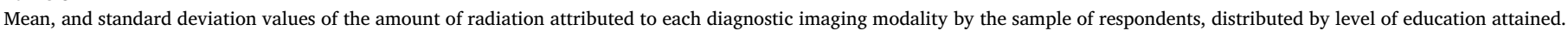

\begin{tabular}{|c|c|c|c|c|c|c|c|c|c|}
\hline \multirow[b]{2}{*}{ Education level } & \multicolumn{3}{|c|}{ Ultrasound } & \multicolumn{3}{|c|}{ Mammography } & \multicolumn{3}{|l|}{ X-rays } \\
\hline & Middle & High & University & Middle & High & University & Middle & High & University \\
\hline Mean & 1.6 & 1.8 & 1.7 & 3.8 & 5.3 & 4.9 & 7.9 & 7.4 & 7.5 \\
\hline St. Dev & 1.2 & 1.7 & 1.5 & 3.0 & 3.0 & 3.0 & 1.8 & 2.5 & 2.4 \\
\hline
\end{tabular}

\begin{tabular}{|c|c|c|c|c|c|c|}
\hline \multirow[b]{2}{*}{ Education level } & \multicolumn{3}{|l|}{ MRI } & \multicolumn{3}{|l|}{$\mathrm{CT}$} \\
\hline & Middle & High & University & Middle & High & University \\
\hline Mean & 6.5 & 5.2 & 4.7 & 7.4 & 6.6 & 7.0 \\
\hline St. Dev & 3.9 & 3.4 & 3.6 & 3.5 & 3.3 & 3.2 \\
\hline
\end{tabular}


Table 6

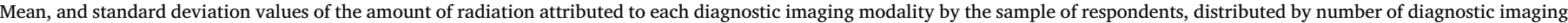
procedures taken in the three years prior to questionnaire administration.

\begin{tabular}{|c|c|c|c|c|c|c|c|c|c|c|c|c|c|c|c|}
\hline \multirow[b]{2}{*}{ Number of procedures } & \multicolumn{3}{|c|}{ Ultrasound } & \multicolumn{3}{|c|}{ Mammography } & \multicolumn{4}{|c|}{$\mathrm{X}$-rays } & \multicolumn{2}{|l|}{ MRI } & \multicolumn{3}{|l|}{$\mathrm{CT}$} \\
\hline & 0 & 1 & $>1$ & 0 & 1 & $>1$ & 0 & 1 & $>1$ & 0 & 1 & $>1$ & 0 & 1 & $>1$ \\
\hline Mean & 2.0 & 2.3 & 1.8 & 4.2 & 4.3 & 5.3 & 7.0 & 6.8 & 7.4 & 4.9 & 5.8 & 5.2 & 6.5 & 7.1 & 6.8 \\
\hline St. Dev & 1.7 & 2.3 & 1.7 & 2.6 & 3.0 & 3.0 & 2.9 & 2.6 & 2.5 & 3.3 & 3.3 & 3.6 & 3.2 & 2.9 & 3.2 \\
\hline
\end{tabular}

Table 7

Consistency questions grouped by age, education and number of diagnostic exams received by patients in the last three years.

\begin{tabular}{|c|c|c|c|c|c|c|c|c|c|c|}
\hline \multirow[t]{2}{*}{ Consistency questions } & \multicolumn{4}{|c|}{ Age (years) } & \multicolumn{3}{|c|}{ Education } & \multicolumn{3}{|c|}{ Diagnostic exams } \\
\hline & $18-25$ & $26-45$ & $46-65$ & $66-90$ & Middle & High & University & 0 & 1 & $>1$ \\
\hline Ultrasound no IR? & $\mathrm{T}$ & $\mathrm{T}$ & $\mathrm{T}$ & $\mathrm{T}$ & $\mathrm{T}$ & $\mathrm{T}$ & $\mathrm{T}$ & $\mathrm{T}$ & $\mathrm{T}$ & $\mathrm{T}$ \\
\hline MRI dose $=$ ultrasound dose $?$ & $\mathrm{~F}$ & $\mathrm{~F}$ & $\mathrm{~F}$ & $\mathrm{~F}$ & $\mathrm{~F}$ & $\mathrm{~F}$ & $\mathrm{~F}$ & $\mathrm{~F}$ & $\mathrm{~F}$ & $\mathrm{~F}$ \\
\hline MRI dose < radiography dose? & $\mathrm{T}$ & $\mathrm{T}$ & $\mathrm{T}$ & $\mathrm{T}$ & $\mathrm{T}$ & $\mathrm{T}$ & $\mathrm{T}$ & $\mathrm{T}$ & $\mathrm{T}$ & $\mathrm{T}$ \\
\hline MRI dose < Mammography dose? & $\mathrm{F}$ & $\mathrm{F}$ & $\mathrm{T}$ & $\mathrm{F}$ & $\mathrm{F}$ & $\mathrm{T}$ & $\mathrm{T}$ & $\mathrm{F}$ & $\mathrm{F}$ & $\mathrm{T}$ \\
\hline MRI dose < CT dose? & $\mathrm{T}$ & $\mathrm{T}$ & $\mathrm{T}$ & $\mathrm{T}$ & $\mathrm{T}$ & $\mathrm{T}$ & $\mathrm{T}$ & $\mathrm{T}$ & $\mathrm{T}$ & $\mathrm{T}$ \\
\hline Radiography dose < CT dose? & $\mathrm{T}$ & $\mathrm{F}$ & $\mathrm{F}$ & $\mathrm{T}$ & $\mathrm{T}$ & $\mathrm{F}$ & $\mathrm{F}$ & $\mathrm{F}$ & $\mathrm{F}$ & $\mathrm{F}$ \\
\hline
\end{tabular}

Table 8

Healthcare professionals contacted by patients to discuss about risks arising from ionizing radiation.

\begin{tabular}{lllll}
\hline Medical physicist & Nurse & GP & Medical Radiologist & Radiology Technician \\
\hline $7.9 \%$ & $1.8 \%$ & $51.1 \%$ & $20.3 \%$ & $21.1 \%$ \\
\hline
\end{tabular}

Table 9

Healthcare professionals patients would ask for information about risks arising from ionizing radiation.

\begin{tabular}{llllll}
\hline $\begin{array}{l}\text { Medical } \\
\text { physicist }\end{array}$ & Nurse & GP & $\begin{array}{l}\text { Medical } \\
\text { Radiologist }\end{array}$ & $\begin{array}{l}\text { Radiology } \\
\text { Technician }\end{array}$ & None \\
\hline $12.9 \%$ & $1.9 \%$ & $26.1 \%$ & $64.7 \%$ & $40.1 \%$ & $2.0 \%$ \\
\hline
\end{tabular}

Table 10

Channels used by the respondents to find information related to the risks arising from ionizing radiation.

\begin{tabular}{llll}
\hline TV & Magazines/Specialised publications & Internet & Other \\
\hline $17.6 \%$ & $24.4 \%$ & $66.5 \%$ & $14.2 \%$ \\
\hline
\end{tabular}

Table 11

Patient orientation in dose reducing compared to image quality enhancement.

\begin{tabular}{lll}
\hline Option & Answers & Percentage \\
\hline Reduce the dose of IR delivered by equipment & 361 & $56.4 \%$ \\
Enhance the quality of diagnostic images & 279 & $43.6 \%$ \\
Total & 640 & \\
\hline
\end{tabular}

Table 12

Patient orientation about the usefulness to have the ionizing radiation dose information stated in the medical report.

\begin{tabular}{lll}
\hline Option & Answers & Percentage \\
\hline Yes & 570 & $84.7 \%$ \\
No & 35 & $5.2 \%$ \\
Don't know & 68 & $10.1 \%$ \\
Total & 673 & \\
\hline
\end{tabular}

respondents in the past three years.

With regard to the subdivision by age groups, it is important to observe that the group of respondents aged 18-25 years old, has higher values for all imaging modalities (with the exception of mammography) than all other population groups. The same goes for the subgroup of respondents who were educated up to middle school. In general, the amount of radiation identified by women is higher (with the exception of ultrasound). Going back to a point already suggested by the evaluations made earlier, the mean values attributed to magnetic resonance imaging by the various groups were always greater than one (which stands for the lack of knowledge of ionizing radiation) across the entire sample, and they were generally comparable to the values attributed to mammography in all subgroups. Moreover, a general inversion versus real data was observed between conventional radiology and CT; the amount of radiation identified for CT was just slightly lower than the amount identified for conventional radiology.

We assessed the consistency across the assignment of values to the various imaging modalities, and extracted the overall mean values assigned by each group compared with the amount assigned to each imaging modality as reported in Table 7.

This analysis seemed partly to confirm what has already been suggested. First of all, we could observe how ultrasound was correctly recognized as an imaging modality that does not involve the use of ionizing radiation. We could confirm how magnetic resonance imaging was wrongly believed to be an imaging modality using sources of X-rays by a majority of the respondents, although with a reduced impact in terms of dose, comparable to mammography. This was further confirmed by the significant difference between the median value assigned to MRI and the one assigned to ultrasound. CT was correctly identified as an imaging modality using X-rays. However, the majority of the participants believed that CT does not involve a greater radiation dose than a conventional radiological exam. Finally, mammography was correctly believed to be an imaging modality using ionizing radiation, but in low dose.

When comparing the various subgroups with one another, we could find some greater awareness in the age group between 45 and 65 years old, and in those who took two or more diagnostic imaging tests. Education did not seem to have any influence on the values expressed by respondents, at least on the basis of this analysis.

With regard to the channels used by patients to find information, it was worth underscoring how only one fourth $(25.4 \%)$ of the respondents discussed with or asked health care professionals for information (question 5). The results are summarized in Table 8. 
The responses of patients changed when they had to tell which health care professional they believed to be the most suitable to provide information. As the Table 9 clearly shows (question 6), two thirds of the respondents would confidently discuss the issues related to the use of ionizing radiation for medical purposes with the medical radiologist, over $40 \%$ would do it with radiology technicians, and only $12.9 \%$ would ask a medical physicist for information.

Similar to what has been found about the number of patients who ask health care staff for information, only $25.8 \%$ of the respondents declared they had voluntarily tried to search for more in-depth information about the issues relating to the risk arising from ionizing radiation. As shown in the Table 10, concerning question 7 , the most widely used media were the Internet and, for only a minority of the respondents, the specialised press and TV.

With regard to the orientation to reduce the dose or to enhance the quality of diagnostic images (question 8), there were no marked preferences, although the first option was slightly preferred as reported in Table 11.

As far as question 9 is concerned, there was an overwhelming majority of the respondents who believed it important to receive a communication about the amount of ionizing radiation delivered for diagnostic purposes in their medical report (Table 12).

\section{Discussion and conclusions}

In radiology, the responsibility to inform patients about their care includes the communication about radiological risks. The Council of the European Union requires that the information relating to patient exposure forms part of the radiological procedure report. This requirement, however, should be understood in the general context of the European Directive, more specifically by following the Foreword n. 28: "This Directive [...] should strengthen the requirements concerning information to be provided to patients, the recording and reporting of doses from medical procedures [...]. It should be noted that according to the World Health Organisation the concept of health is understood to cover the physical, mental and social will-being of an individual and not merely the absence of disease or infirmity" [4]. It follows that a simple inclusion of radiation information in the radiological reports is not enough to properly inform the patients: the real goal of the European regulation is an effective communication. In this regard, our survey indicates that there is a significant gap in patient awareness about ionization radiation risk and that there is a need to address this deficiency.

The statistical analysis carried out on the various survey groups did not show any substantial differences in terms of age, level of education attained, and number of diagnostic procedures taken prior to questionnaire administration. However, women assigned higher values to the amount of radiation attributed to each diagnostic imaging modality, in particular in mammography with likely reference to its large use in female patients. Certainly, those who underwent more than one diagnostic exam and belong to an age group between 45 and 65 years old, seemed to have a greater awareness of the dose received for the different types of diagnostic exams.

Concerning the radiological modalities, we can set forth a few general conclusions. First of all, ultrasound was believed to be an imaging modality that does not use ionizing radiation, with likely reference to its large use in prenatal and paediatric care. However, on the other hand it was wrongly believed that magnetic resonance imaging does use X-rays, albeit in relatively low radiation doses. Second, only $60 \%$ know that mammography is an X-Rays modality. Third, CT was seen as an imaging modality that involves the use of ionizing radiation, however perceived to use lower radiation than conventional radiological exams. Lastly, we observed that the latter was considered the imaging modality that involves the greatest dose of patient radiation exposure of all diagnostic procedures.

With regard to the option between an improvement in the quality of images and a reduction in radiation doses, we did not investigate if participants were aware of the relationship connecting dose reduction and image quality enhancement (enhancing the quality of images may involve a relative dose increase). Purpose of this study was to provide information that can help to plan an effective communication and in this scenario question 8 was designed as exclusionary. Faced with this choice it could be observed how almost half of the respondents believed it is important to optimize the radiological procedure in terms of a reduction in the radiation dose, thus showing an interest which is anything but secondary in the knowledge of this issue.

The finding about the communication of dosimetry data was rather important, a possibility which was thought of as interesting by a majority of the participants. This could be inferred both from the high percentage of respondents who would like to have an optimised exam in terms of dose reduction, and from those who would like to have a statement about dosimetry included in their medical report.

As far as communication is concerned, it was evident that the participants did not know the role of the medical physicists who are the health care professionals who can provide - more than others - accurate information about the effects of ionizing radiation on the human body [22-23]. Moreover, almost 70\% of the respondents already discussed, and they would confidently discuss, the issues related to the use of ionizing radiation in medicine with family physician and radiology technician. This was complemented by the data about the channels used by patients to obtain information. About one third of those who voluntarily searched for information about the risks associated with radiological practices, used the Internet to do so. Effective communication strategies, therefore, cannot neglect the goal of promoting the medical physics discipline, and to convey information accurately using informatics web-based resources [24]: in this scenario, future medical physicist education should include also risk communication. Finally, the data showed the need for a joint effort from all the healthcare professionals. Medical physicists and radiologists may increase the partnership with GP and radiology technician with the goal to design a common communication strategy.

\section{References}

[1] ICRP Publication 1, Recommendations of the International Commission on Radiological Protection, International Commission on Radiological Protection 1958.

[2] ICRP Publication 60, 1990 Recommendations of the International Commission on Radiological Protection, Ann ICRP 1990;21(1-3).

[3] ICRP Publication 103, The 2007 Recommendations of the International Commission on Radiological Protection, Ann ICRP 2007;37(2-4).

[4] COUNCIL DIRECTIVE 2013/59/EURATOM http://eurlex.europa.eu/LexUriServ/ LexUriServ.do?uri = OJ:L:2014:013:0001:0073:IT:PDF.

[5] State of California, Senate Bill No. 1237 Approved By Governor September 29, 2010.

[6] European Society of Radiology (ESR). Summary of the European Directive 2013/ 59/Euratom: essentials for health professionals in radiology. Insights Imaging 2015;6.

[7] Portelli JL, McNulty JP, Bezzina P, Rainford L. Paediatric imaging radiation dose awareness and use of referral guidelines amongst radiology practitioners and radiographers. Insight Imaging 2016;7.

[8] Simeonov G. European activities in radiation protection in medicine. Radiat Prot Dosimetry 06/2015;165(1-4).

[9] Economides S, Boziari A, Vogiatzi S, et al. Prevention of and response to inadvertent exposure of embryo/fetus to ionizing radiation, due to medical exposure of the mother. The Greek regulatory authority initiatives. Physica Medica 2014;30(2).

[10] ICRP Publication 105, Radiological Protection in Medicine, Ann ICRP 2007;37(6).

[11] O'Connor M. Risk of Low-dose Radiation and the BEIR VII Report: A critical review of what it does and doesn't say, Physica Medica 2017;40 (in press).

[12] Andrés C, Pérez-García H, Agulla M, Torres R, Miguel D, del Castillo A, et al. Patient doses and occupational exposure in a hybrid operating room. Physica Med 2017;37.

[13] Safari MJ, Ding Wong JH, Loong Jong W, Thorpe N, Cutajar D, Rosenfeld A, Hoong $\mathrm{Ng} \mathrm{K}$. Influence of exposure and geometric parameters on absorbed doses associated with common neuro-interventional procedures. Physica Medica 2017;35.

[14] Picano E. Rischio-beneficio nella diagnostica per immagini: impatto dell'utilizzo di radiazioni ionizzanti. Giornale Italiano di Cardiologia 2008;9(12).

[15] Paolicchi F, Miniati F, Bastiani L, et al. Insights Imaging 2016;7.

[16] Lee CI, Haims AH, Monico EP, Brink JA, Forman HP. Radiology 2004;232(2).

[17] Heyer CM, Hansmann J, Peters SA, Lemburg SP. Paediatrician awareness of radiation dose and inherent risks in chest imaging studies - a questionnaire study. Eur J Radiol 2010;76(2). 
[18] Sin H, Wong C, Huang B, Yiu K, Wong W, Chu YCT. Assessing local patients' knowledge and awareness of radiation dose and risks associated with medical imaging: a questionnaire study. J Med Imaging Radiat Oncol 2013;57.

[19] Puri S, Hu R, Quazi RR, Voci S, Veazie P, Block R. Physicians' and midlevel providers' awareness of lifetime radiation-attributable cancer risk associated with commonly performed CT studies: relationship to practice behavior. Am J Roentgenol 2012;199(6).

[20] Lam DL, Larson DB, Eisenberg JD, Forman HP, Lee CI. Communicating potential radiation-included cancer risks from medical imaging directly to patients. Am J Roentgenol 2015;205(5).

[21] Di Piazza, Vernuccio F, Murmura E, Scopelliti L, et al. Patients' knowledge and awareness of radiation dose and risks from CT: do patients need a personalized communication of dose bill? Eur Congr Radiol 2015, C-0334.

[22] Caruana CJ, Christofides S, Hartmann GH. European Federation of Organisations for Medical Physics (EFOMP) Policy Statement 12.1: Recommendations on Medical Physics Education and Training in Europe 2014. Physica Medica 2014;30(6).

[23] Evans S, Christofides S, Brambilla M. The European Federation of Organisations for Medical Physics. Policy Statement No. 7.1: The roles, responsibilities and status of the medical physicist including the criteria for the staffing levels in a Medical Physics Department approved by EFOMP Council on 5th February 2016. Physica Medica 2016;32(4)

[24] Freudenberg LS, Beyer T. Subjective perception of radiation risk. J Nucl Med 2011;52(12). 